\title{
ULTRASTRUCTURE OF HYPHAE IN GIGASPORA ALBIDA Schenck \& Smith (GLOMALES)
}

\author{
Leonor C. Maia*, James W. Kimbrough**, \& Gerall Benny** \\ * Departamento de Micologia, Centro de Ciências Biológicas, \\ Universidade Federal de Pernambuco, 50670-420 Recife, \\ PE, Brasil \\ ** Department of Plant Pathology, 1453 Fifield Hall, IFAS, \\ University of Florida, 32611, Gainesville, Florida, USA.
}

Palabras clave: citologia, núcleo, arbuscular micorriza, endomicorriza, Glomales.

Key words: cytology, nucleus, arbuscular mycorrhizae, endomycorrhizae, Glomales.

\section{SUMMARY}

Studies were performed to describe the ultrastructure of hyphae in Gigaspora albida. There is an even distribution of cytoplasmic organelles with nuclei interspaced with vacuoles and polyphosphate granules in the hyphae. Evidences indicated that nuclear condition changes after germ tube formation. No clear proof of meiotic or mitotic processes were found, but elongated muclei, presence of nucleus associated organelles, and a line of division in the central region of some of the nuclei were demonstrated.

\section{INTRODUCTION}

Arbuscular mycorrhizal fungi are obligated symbiotic organisms which have an important role in natural agroecosystems since they constitute a key component of the rhizosphere (Lindermann, 199) and increase plant growth (Mosse \& Hayman 1980). The new order Glomales (Zygomycotina), erected to include these fungi(Morton \& Benny, 1990) is formed by six genera where sexual nature of the spores is not clear. Species of the genera Gigaspora form spores on bulbous suspensor like cells. Gerdemann \& Trappe (1974), described these spores as azygospores, since they appeared to be formed on parthenogenetic gametangia. The azygosporic nature

\section{RESUMEN}

[Ultraestructura de la hifa en Gigaspora albida Schnck \& Sinith (Glomales)]

Se efectuaron estudios para determinar la ultraestructura de las hifas en Gigaspora albida. Se observó una distribución regular de los organelos citoplasmáticos, con nucleos interespaciados con vacuolas y granos de polifosfato. Las evidencias indicaron que la condición nuclear cambia después de la formación del tubo germinativo. No se encontró ninguna prueba de procesos meióticos o mitóticos, pero se observó la presencia de núcleos alargados, una linea divisoria en la región central de algunos de éstos y organelos asociados al núcleo.

was accepted by some authors (Schenck \& Pérez 1990; Morton \& Benny 1990), while others considered that once the teleomorphic or anamorphic nature is not known they should be called simply spores (Walker, 1987). Tommerup\& Sivasithamparam (1990), mentioned these spores as conidia. A different and smaller spore, formed by Gigaspora decipiens Hall \& Abbott was described as zygospore by Tommerup (1988).

Understanding of reproductive events and nuclear behavior are limited in Zvgomycetes, especially in Glomales. Studies of ultrastructure to clarify the processes of spore formation, hyphal development and nuclear cycle are difficult mostly due to problems with fixation, staining, and embedding of arbuscular mycorrhizal fungi 
(Mosse, 1986; Maia et al. 1993a). Consequently, most of the studies have been centered in wall structure or anatomy of the endomycorrhizal interaction, which are easier to process for electron microscopy. A few papers reported the germination process on spores of some Acaulospora, Glomus, Gigaspora, and Scutellospora species (Gibson, 1985; Maia et al., 1994; Meier \& Charvat, 1992; Mosse, 1970a, 1970b; Old et al., 1973; Sward, 1981b).

During ultrastructural studies on germ tubes of Glomus mosseae (Nicol.\& Gerd.) Gerdemann \& Trappe; Meier \& Charvat (1992), found numerous fusoid nuclei with nucleoli, elongate mitochondria, and both osmiophilic and osmiophobic lipid droplets. The multinucleate condition of spores, hyphae, auxiliary cells, vesicles and arbuscules in different species of Glomales have been described (Bonfante-Fasolo et al., 1981: Burggraaf \& Beringer 1987; Cooke et al., 1987; Mosse 1970a: Scannerini \& Bonfante-Fasolo, 1975; Sward, 1981b). However, the nature of the nuclei, whether homokaryotic or heterokaryotic needs to be determined. With TEM studies, the significance of the multinucleate state could be understood. This would demonstrate possible relationships among members of Glomales and the other $Z$ ygomycetes. Knowledge of nuclear structure in fungi has greatly increased with TEM studies even considering known methodological limitations (Beakes, 1981). The objective of this research was to describe ultrastructure of hyphae in Gigaspora albida Schenck \& Smith. Nuclear phenomena were studied: wall and cytoplasmic organelles were described and compared with that found in other Glomales.

\section{MATERIALS AND METHODS}

\section{Cultural procedures}

An isolate of Giguspora albida (GABD 927) from the International Culture Collection of VAM fungi (INVAM) was pot-cultured in a medium consisting of a mixture of $3: 1(\mathrm{v} / \mathrm{v})$ sand and vermiculite (Liyanage, 1989), associated with Bahia grass (Paspalum notatum Flugge). The pot cultures received Long Ashton nutrient solution (Hewitt, 1966) every other day and were maintained in a growth room with artificial mercury light (400 to $600 \mu \mathrm{mol} . \mathrm{cm}^{-2} \mathrm{sec}^{-1}$ ) of $1 \mathrm{~h}$ length, with a temperature range of $26^{\circ} \mathrm{C}$, night and $28^{\circ} \mathrm{C}$, day. Spores were isolated from pot cultures by wet sieving and decanting (Gerdemann \& Nicolson 1963), followed by centrifugation in $40 \%(\mathrm{w} / \mathrm{v})$ sucrose (Jenkins, 1964) and were allowed to germinate before fixation.

\section{Germination}

Selected spores of GABD 927 were washed in water, and separated. A group wassuperficially disinfected with $0.5 \% \mathrm{NaOCl}$ ( $10 \%$ Chlorox) for $2 \mathrm{~min}$, while the other group was not disinfected. All spores were placed in petri dishes with $1 \%$ water agar + thiamine at $0.1 \mathrm{mg} /$ $\mathrm{L}^{-1}$ and allowed to germinate. Plates were incubated at room temperature $\left(25^{\circ} \mathrm{C}\right)$ in the dark. Spores were observed every other day and were considered germinated with emergence of a germ tube.

\section{Transmission electron microscopy}

Germinating spores and hyphae were embedded in molten $2 \%$ agarose. Narrow strips of agarose containing a few germinated spores and hyphae were cut with a razor blade and processed for fixation. Fixatives used were $7.2 \%$ glutaraldehyde for $2 \mathrm{~h}$ at room temperature or a solution of $2 \%$ glutaraldehyde plus $2 \%$ formaldehyde. made from paraformaldehyde in $0.2 \mathrm{M}$ sodium cacodylate buffer, overnight at $5 \mathrm{C}$. After postfixation in $1 \%$ osmium tetroxide and dehydration in an ethanol series followed by acetone (Benny \& Aldrich 1975). specimens were embedded in ERL 4206 resin (Spurr, 1969).

Embedded material was incubated at $60^{\circ} \mathrm{C}$ for $48 \mathrm{~h}$ for two days, for polymerization. Blocks were sectioned with a diamond knife on an LKB ultramicrotome and ultrathin sections collected on one hole formvar-coated copper grids. Sections were post-stained for $40 \mathrm{~min}$ in $2 \%$ (w/v) aqueous uranyl acetate followed by $5 \mathrm{~min}$ in Reynolds (1963) lead citrate, and observed with a JEOL $100 \mathrm{CX}$ electron microscope at $60 \mathrm{kV}$.

\section{RESULTS}

The hyphal wall (Fig. 1,2) is comparatively thinner then that reported for the spore wall, which has many laminated layers (Maia et al., 1994). The hyphal wall consisted of only two layers, the inner thicker and electron dense, the outer thinner and with adherent particles (Fig. 2). A broader view of the hyphae indicated an even distribution of cytoplasmic organelles with nuclei fairly evenly interspaced with vacuoles and polyphosphate granules (Fig. 1). The vacuoles were of various sizes and shapes, with presence of content varia. bles (Fig. 2). Sometimes, vacuoles seemed to enclose cytoplasmic structures such as electron dense globules, myelin figures, and polyphosphate granules (Figs. 1-3). 


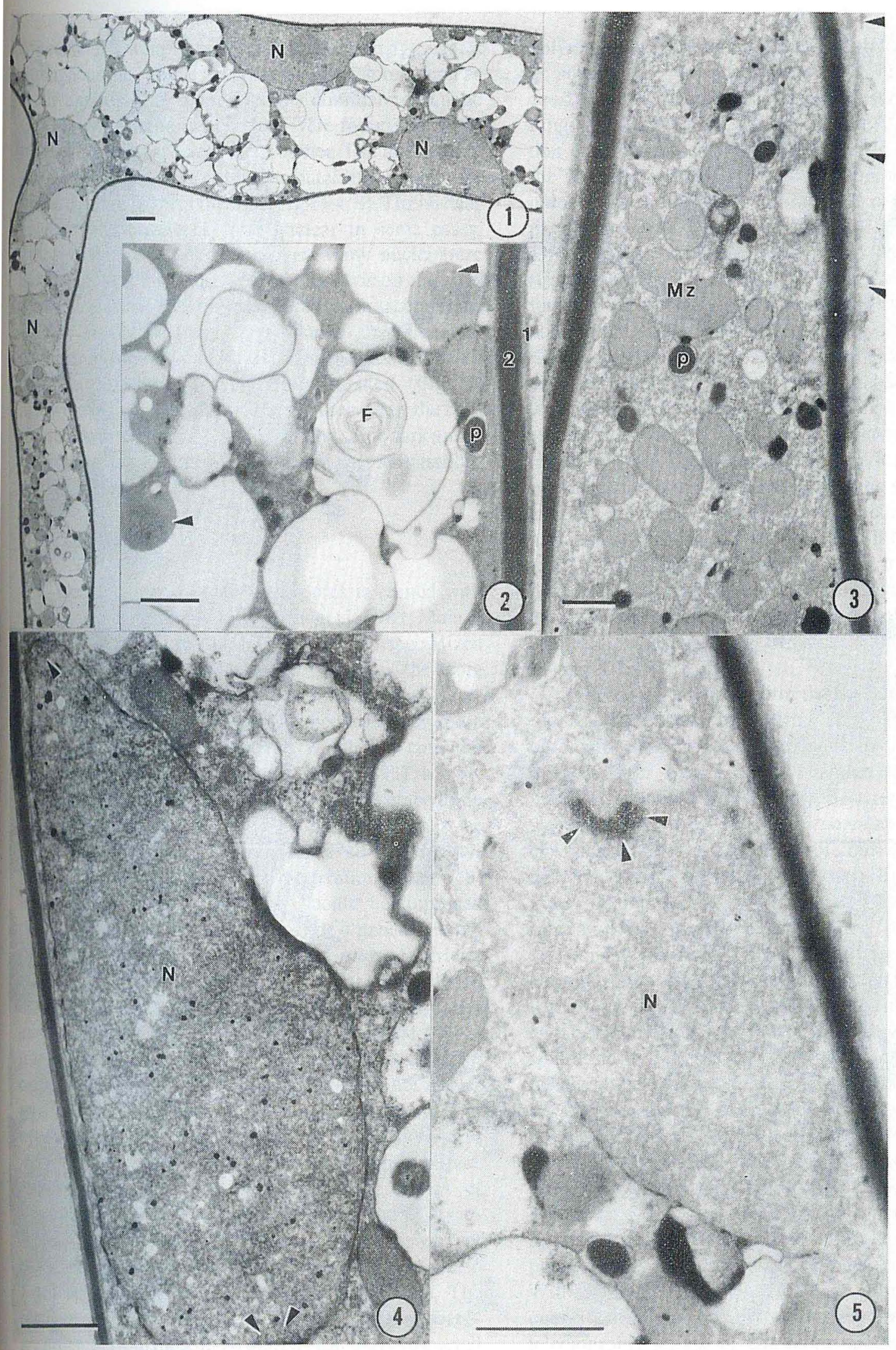

Text in page 63 


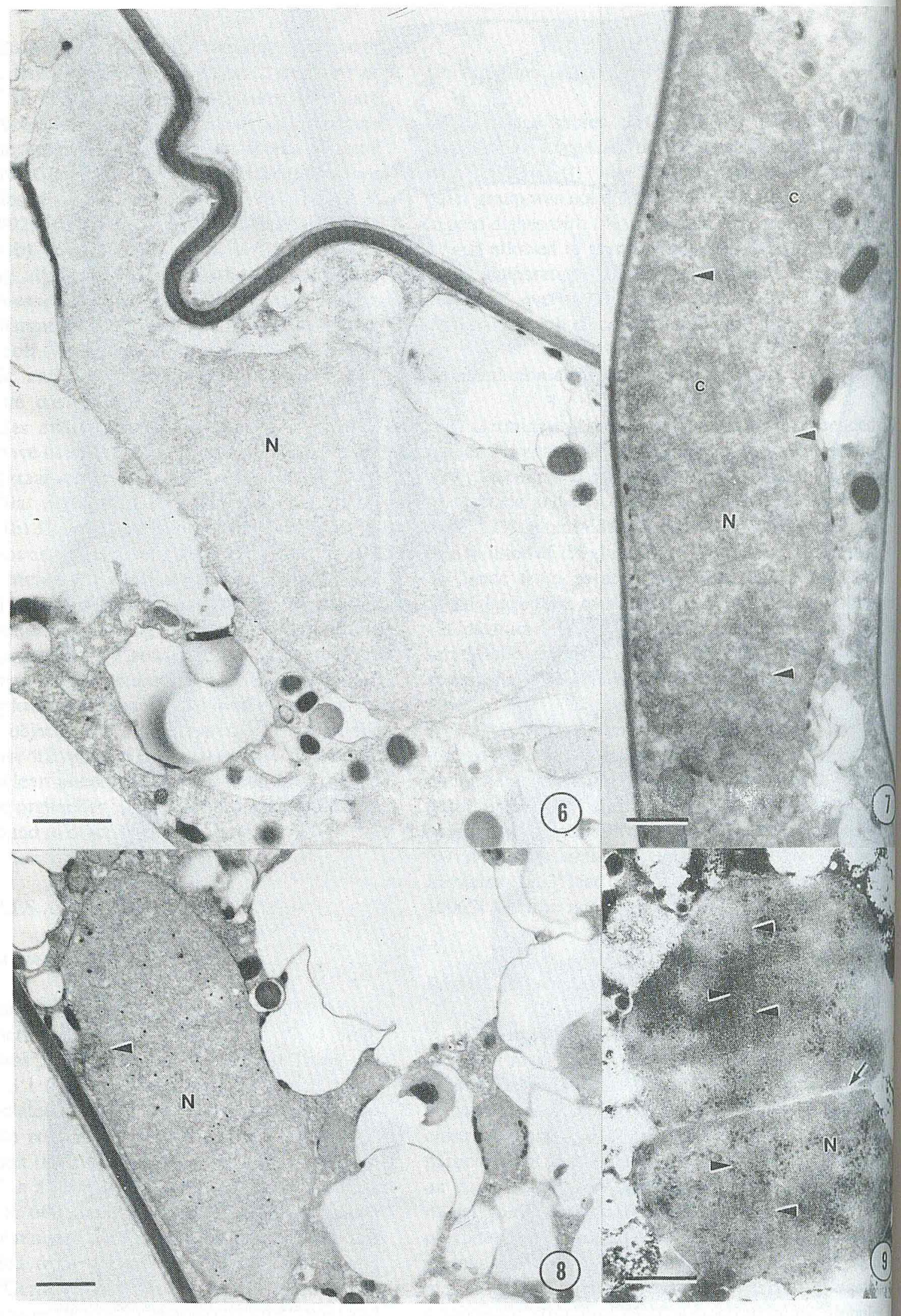

\section{Text in page 63}


Mitochondria were isolated or distributed in aggregates throughout the hyphae. In some hyphal regions such as the hyphal tip, they seem to be the dominant organelle (Fig. 3) Mitochondria generally were round, but some were elongated, especially near nuclei. The nuclei were polymorphic and generally distributed throughout the hypha or localized near the wall (Figs. 1,4,8). The nuclear contents and envelopes were unclear in some cases, probably due to fixation problems. Many nuclei were elongated, as if they were undergoing division (Figs. 48). Some electron dense bands were seen adjacent to the nuclear membrane (Figs. 5, 8), and in one specimen condensed chromatin and microtubules associated with division could be vaguely distinguished (Fig. 7 . arrowheads). A clear division was observed in the central region of certain nuclei (Fig. 9) and some dark areas, interpreted as condensed chromatin were seen distributed in the nuclei.

\section{DISCUSSION}

Germination of Gigaspora spores is related with formation of a germinal wall (Spain et al.,1989; Maia et al.,1994). The germ tubes emerge from specialized compartments within the innermost layers of the spore wall, usually in the region near the subtending hyphae. In general many germ tubes are formed from each spore in $G$. albida (Maia et al.,1994), which is a common phenomenon in Gigaspora spores (Koske. 1981: Mosse. 1959). Several techniques for fixation and embedding were attempted before satisfactory results could be obtained in G. albida and it was observed that for hyphae the traditional gluteraldehyde fixation works well; however for spores technology should be improved (Maia et al.,1993a). Many of the same organelles found in G. albida were reported in Glomus mosseae (Meier \& Charvat, 1992). Most of the vacuoles enclosed cytoplasmic structures such as polyphosphate granules and electron dense globules. Meier \& Charvat (1992) interpreted the electron translucent vacuoles as being osmiophilic lipid droplets. However, they do not appear to accumulate the electron dense material reported in hyphae of some species of Glomus (Maia, 1991) and in Acaulospora laevis Gerdemann \& Trappe (Mosse. 1970b). The large crystals reported in spores of Acaulospora laevis (Mosse, 1970b. 1970c) and Gigaspora margarita Becker \& Hall (Sward, 1981a) were not observed in G. albida . Absence of such crystals was also noted in $G$. mosseae (Meier \& Charvat. 1992). The pigment granules reported by Mosse (1970c) probably are different from those in G. albida, which are suspected of being polyphosphate granules (Gibson 1985).
Polyphosphates are found in fungi both as granules and as soluble polyphosphate (Martin et al., 1983), and constitute the primary phosphorus reserve for many fungi (Beever \& Burns, 1980). Tinker (1975), suggested that polyphosphate containing vacuoles are carried by the streaming cytoplasm and continuously load and unload their contents, to balance the concentration of phosphorus in the cytoplasm. Later, within the internal mycelium, the polyphosphate disappears from the vacuoles (Cappacio \& Callow, 1982), indicating it has been, transferred to the host. We found no evidences to confirm this observation. Elongated nuclei as found in hyphae of $G$. albida were also a consistent feature in hyphae of $G$. mosseae (Meier \& Charvat, 1992). Such nuclei or those with blebs, may correspond to anaphase stages or can result from the flow of the cytoplasmic streaming (Beakes,1981). The electron dense bands adjacent to the nuclear membrane, appear to be grazing sections of the spindle pole bodies, also called nucleus associated organelles or NAOs (Beakes 1981; Heath 1981a, 1981b).

In most $Z$ ygonycetes, the nuclear envelope remains intact during the division process and the NAOs are truly intranuclear (Beakes. 1981). In some Mucorales, NAOs are associated with the inner nuclear membrane (Bland \& Lunney, 1975).

Dark areas distributed in the nucleus are interpreted as condensed chromatin. The phenomenon of chromatin condensation occurs normally during mitosis in most fungi (Heath, 1980). Features observed in the nuclei of $G$.albida are similar to those reported in other Zygomycetes, especially Mucorales. There, the chromosomes are not recognizable during mitosis, the nucleolus is persistent, and the NAOs are attached to the inner membrane of the nuclear envelope (Bland \& Lunney, 1975).

In $Z$ ygomycetes, vegetative nuclear divisions are definitely mitotic (Beakes, 1981). Heath (1980) suspects that Mucorales may have the most primitive type of eukaryotic division. The mitotic process is simple, with spindle developing entirely from intranuclear NAOs and nuclear envelope remaining intact. Glomales probably have also a simple process of undergoing mitosis. Studies of meiosis are not common, particularly in Zygomycetes (Beakes, 1981), and in Glomales there is no proof that it occurs. Using morphological features, Tommerup \& Sivasithamparam (1990), considered small spores formed by G. decipiens Hall \& Abbott as zygospores. However, cytological evidence still is missing. Without evidence of synaptonemal complexes or the quantification of nucleic acids, the anamorphic or teleomorphic nature of Glomales spores will remain unresolved. However, recent data obtained from studies 
with Glomus versiforme (Karsten) Bench, have shown that duplication of DNA does not occur in the dormant spores but only during the fungus hyphal phase (Bianciotto et al., 1993).

In order to demonstrate evidence of fusion or division processes in arbuscular mycorrhizal fungi, spores may need to be fixed periodically at successive stages. Also, better methods for fixation, staining and embedding of nuclear structures must be developed. Standard fixation and staining processes did not provide good enhancement of nuclear structures. Many of the fixation processes used for TEM produce artefacts or do not preserve certain specific structures (Beakes, 1981; Maia et al.,1993a). Extensive serial sectioning is necessary for obtaining a complete picture of the nucleus and its NAOs, and this is more difficult in fungi where nuclear divisions often are very rapid (Beakes, 1981). More studies will be necessary to disclose the secret of formation of spores in Glomales and their sexual nature, and descriptions of nuclear condition in hyphae could be a way to understand this process.

\section{ACKNOWLEDGEMENTS}

The technical assistance provided by Dr. G. Erdos and staff of the Electron Microscopy Core Laboratory(University ofFlorida, Gainesville) was greatly appreciated. We thank Drs. D. A. Roberts and D. H. Hubbell for reviewing the manuscript, and Ms. Litzu Li for darkroom assistance. L. C. Maia acknowledges grant support from CAPES and CNPq.

\section{REFERENCES}

Beakes, G. W. (1981). Ultrastructure of the phycomycete nucleus. Pp. 135. In: The fungal nucleus. Eds., K. Gull and S. G. Oliver. Cambridge University Press, Cambridge.

Beever, R. E. \& Burns, D. J. W. (1980). Phosphorus uptake, storage and utilisation by fungi. Adv. Bot. Res. 8: 127-219.

Benny, G. \& Aldrich, H. C. (1975). Ultrastructural observations on septal and meros porangial ontogeny in Linderina pennispora (Kickellales; Zygomycetes). Canad. J. Bot. 53: 2325-2335.

Bianciotto, V., Barbiero, G. \& Bonfante, P. (1993). Flow cytometric analysis of nuclei released from spores and intraradical hyphae of Glomus versiforme. In Abstracts of the 9th North American Conference on Mycorrhizae (ed. L. Peterson \& M. Schelkle). p. 127. University of Guelph: Guelph, Ontario.

Bland, C. E. \& Lumey, C. Z. (1975). Mitotic apparatus of Pilobolus erystallinus. Cytobiologie 11:382-391.

Bonfante-Fasolo,P., Dexheimer,J., Gianninazzi,S., Giamninazzi-Person,B., Scamnerini,P. (1981). Cytochemical modifications in the host-fungus interfase during intracellular interactions in vesiculararbuscular mycorrhiza. Pl.Sci.Lett. 22:13-21

Burgraff,A.J.P. \& Beringer, J. E. (1987). Nuclear division and VAmycorrhizal in vitro culture. In:Sylvia.D.M..Hung.L.L. \& Graham. J.H. (Eds.) Proceedings of the 7th North American Conference on Mycorrhizae. Univ of Florida Press. Gainesville. Florida, pp. 190

Cappacio, C. M. \& Callow, J. A. (1982). The enzymes of polyphosphate metabolism in vesicular-arbuscular mycorrhizas. New Phytol. 91 : $81-91$

Cooke, J.C., Gemma, J.N., Koske, R.E.(1987). Observations of nuclei in vesticular-arbuscular mycorrhizal fungi. Mycologia 79: 331 333

Gerdemann, J. WV. \& Nicolson, T. H. (1963). Spores of mycorrhizal Endogone extracted from soil by wet sieving and decanting. Trans. Brit. Mycol. Soc. 46: 235-244.
Gerdemann, J. W. \& Trappe, J. M. (1974). The Endogonaceae in the Pacific Northwest. Mycologia Mem. 5: 1-76.

Gibson, J. (1985). Morphology, cytology, and ultrastructure of selected species of Endogonaceae (Endogonales: Zygomycetes). PhD Dissertation. University of Florida, Gainesville. 166pp.

Heath, I. B. (1980). Fungal mitosis, the significance of variations ona theme. Mycologia 72: 229-250.

Heath, I. B. (1981 a). Mechanisms of nuclear division in fungi. Pp. 85 . 112. In: The fungal nucleus. Eds., K. Gull, and S. Oliver. Cambridge University Press, Cambridge.

Heath, I. B. (1981b). Mitosis through the electron microscope. Pp. 245. 275. In: Mitosis and cytokinesis. Eds., A. Zimmerman and A Forer. Academic Press, New York.

Heath, I. B. (1981c). Nucleus-associated organelles in fungi. Int. Rey. Cytol. 69: 191-221.

Hewitt, E. J. (1966). Sand and water culture methods used in the study of plant nutrition. Pp. 187-237. Commonwealth Agricultural Bureaux. Farnhan Royal, United Kingdom.

Jenkins, W. R. (1964). A rapid centrifugal-flotation technique for separating nematodes from soil. Pl. Dis. Reporter 48: 692.

Koske, R. E. 1981). Gigaspora gigantea: observations on spore gemination of a VA mycorrhizal fungus. Mycologia 78: 288 300 .

Lindermann, R. G. (1991). Mycorrhizal interactions in the rhizosphere Pp. 343-348. In: The rhizosphere and plant growth. Eds., D. L Keister, and P. B. Cregan. Kluwer Academic Publishers, the Netherlands.

Liyanage, H. D. (1989). Effect of phosphorus nutrition and host specis on root colonization and sporulation by VA mycorrhizal fungi in sand vermiculite medium. M.S. Thesis, University of Florida, Gainesville. 
Maia, L. C. (1991). Morphological and ultrastructural studies on spores and germ tubes of selected arbuscular mycorrhizal fungi. (Glomales). PhD Dissertation, University of Florida, Gainesville.

Maia, L. C., Kimbrough, J. W. \& Erdos, G. (1993a). Problems with fixation and embedding of arbuscular mycorrhizal fungi (Glomales). Mycologia 85: 323-330.

Maia, L. C., Kimbrough, J. W. \& Erdos, G. (1993 b). Ultrastructural studies on the spore wall of Gigaspora albida (Glomales) Mycologia 85:883-889

Maia, L. C., Kimbrough, J. W. \& Benny, G. (1994). Ultrastructure of spore germination in Gigaspora albida (Glomales). Mycologia 85: 883-899.

Martin, F., Canet, D., Rollin, D., Marchal, J. P. \& Larner, F. (1983). Phosphorus 31 nuclear magnetic resonance study of polyphosphate metabolism in mycorrhizal fungi. Pl. \& Soil 71: 469-476.

Meier, R. \& Charvat, 1. 1992. Germination of Glomus mosseae spores: Procedure and ultrastructural analysis. Int. J. Pl. Sci. 153: 541549.

Morton, J. B. \& Benny, G. L. (1990). Revised classification of arbuscular mycorrhizal fungi (Zygomycetes): A new order, Glomales, two new suborders, Glomineae and Gigasporineae, and two new families, Acaulosporaceae and Gigasporaceae, with an emendation of Glomaceae. Mycotaxon 37: 471-491.

Mosse, B. (1959). The regular germination of resting spores and some observations on the growth requirements of an Endogone sp. causing vesicular arbuscular mycorrhiza. Trans. Brit. Mycol. Soc. 42: $273-286$

‥-‥-.-. (1970a). Honey colored. sessile Endogone spores. I. Life history. Arch. Mikrobiol. 70: 167-175.

(1970b). Honey-colored, sessile Endogone spores. II. Changes in fine structure during spore development. Arch. Mikrobiol. 74: 129-145.

(1970c). Honey colored, sessile Endogone spores. III. Wall structure. Arch. Mikrobiol. 74: 146-159.

-.-.-. \& Hayman, D. S. (1980). Mycorrhiza in agricultural plants. Pp. 213-230. In: Tropical mycorrhiza research. Ed., P. Mikola. Clarendon Press, Oxford.
(1986). Ultrastructure of the spore wall in some VA-mycorrhizal fungi. In: Gianninazzi-Pearson \& Gianninazzi,S.(Eds.) Physiological and genetical aspects of mycorrhizae. INRA Press, Paris, pp.615-620

Old, K. M., Nicolson, T. H. \& Hedhead, J. F. (1973). A new species of mycorrhizal Endogone from Nigeria with a distinctive spore wall. New Phytol. 72: 817-823.

Reynolds, E. S. (1963). The use of lead citrate at high $\mathrm{pH}$ as an electron opaque stain in electron microscopy. J. Cell. Biol. 17: 202-208.

Scannerini, S. \& Bonfante-Fasolo, P. (1975). Dati preliminari sull' ultrastruttura ultracellulare nelle endomicorrize di Ornithogalum umbellatum L. Atti. Acc.Sci.Torino 109:619-621

Schenck, N. C. \& Pérez, Y. (1990). Manual for the identification of VA mycorrhizal fungi. Synergistic Publ., Gainesville, Florida. 286 pp.

Spain, J.L., Sieverding,E., Schenck, N. (1989). Gigaspora ramisporophora: a new species with novel sporophores from Brasil. Mycotaxon 34:667-677

Spurr, A. R. (1969). A low_viscosity epoxy resin embedding medium for electron microscopy. J. Ultrastruct. Res. 26:31-43.

Sward, R. J. (1981 a). The structure of the spores of Gigaspora margarita. I. The dormant spore. New Phytol. 87: 761-768.

Sward, R. J. (1981b). The structure of the spores of Gigaspora margarita. II. Changes accompanying germination. New Phytol. 88: 661-666.

Tinker, P. B. (1975). The soil chemistry of phosphorus and mycorrhizal effects on plant growth. Pp. 353-372. In: Endomycorrhizas. Eds., F. E. Sanders. B. Mosse, and P. B Tinker. Academic Press, London.

Tommerup, I. C. (1988). The vesicular arbuscular mycorrhizas. Pp.8192. In: Advanced Plant Patholology Vol. 6. Ed., G. S. Sidhu. Academic Press, London.

Tommerup, 1. C. \& Sivasithamparam, K. (1990) Zygospores and asexual spores of Gigaspora decipiens, an arbuscular mycorrhizal fungus. Mycol. Res. 94: 897-900.

Walker, C. (1987). Current concepts in the taxonomy of the Endogonaceae. Pp. 300-302. In: Mycorrhizae in the Next Decade, Practical Applications and Research Priorities. Proceedings of the 7th North American conference on mycorrhizae. Eds., D. M. Sylvia, L.L. Hung, and J. H. Graham. Institute of Food and Agricultural Sciences. University of Florida, Gainesville.

FIGS. 1-5. Transmission electron micrographs of developed germ tubes of Gigaspora albida (GABD 927). 1. General view of hypha showing distribution of nuclei $(\mathrm{N})$ and other organelles. Scale bar $=1 \mathrm{um}$. 2. A hyphal segment with well defined 2-layered wall $(1,2)$, containing vacuoles with apparent myelin figures $(\mathrm{F})$ and others with opaque bodies (arrowhead) and polyphosphate granules $(\mathrm{P})$. Scale bar $=0.5 \mathrm{um}$. 3 . Detail of mitochondrial zone (Mz) in a hypha with many polyphosphate granules (p). Outer wall is sloughing (arrowheads). Scale bar $=0.5 \mu \mathrm{m}$. 4 . An elongate nucleus located near the hyphal wall, with electron dense, unidentified material (arrowhead) near its poles. Scale bar $=0.5 \mu \mathrm{m}$. 5 . Nucleus $(\mathrm{N})$ with electron dense band (arrowheads) adjacent to the nuclear membrane, that may be nucleus associated organelles (NAOs). Scale bar $=0.5 \mu \mathrm{m}$

FIGS. 6-9. Transmission electron micrographs of a hypha of Gigaspora albida (GABD 927). 6. An elongate nucleus (N). Scale bar $=0.5 \mu \mathrm{m}$. 7. Nucleus with microtubules (arrowheads) and condensed chromatin (c). Scale bar $=0.5 \mu \mathrm{m}$. 8. General aspect of a hypha with a nucleus localized near the wall. Putative NAOs are positioned adjacent to the nuclear envelope (arrowhead). Scale bar $=0.5 \mu \mathrm{m}$. 9 . Anucleus $(\mathrm{N})$ which appears to be dividing in the central region of a hypha (arrow). Scale bar $=0.5 \mu \mathrm{m}$. 